\title{
Editorial \\ La Ética del siglo XXI
}

Faride ZERÁN*

En los debates sobre la formación de comunicadores en el nuevo milenio suele surgir como un desafío, pero a la vez como una suerte de encantamiento, el tema de las nuevas tecnologías de la información y la comunicación (NTIC). Desde la ventana seductora de Internet, como icono de la globalización, pero también desde los renovados dispositivos audiovisuales, se invita a las universidades a incorporar nuevos equipos y nuevos lenguajes. Se las conmina a capacitar a los futuros periodistas, cineastas, comunicadores audiovisuales y comunicadores organizacionales (por citar algunas referencias en una terminología in crescendo) con destrezas en el manejo de sofisticados instrumentos de registro y transmisión, para "no quedarse atrás" en un "mundo real" donde irrumpen productos mediáticos no convencionales y los mensajes se sumen en la hibridez de formatos, géneros y funciones. Los profesionales de la prensa ya no tienen el "monopolio" de la información, mientras los redactores y editorialistas de antaño son desplazados por "opinólogos" que irrumpen de la mano con la mercantilización de la industria de los medios. Pero es que también fenómenos como los blogs y los sitios gestados desde organizaciones de la sociedad civil proponen que todos podemos ser reporteros ciudadanos y del mismo modo colocar legítimamente nuestros comentarios y juicios en los espacios infinitos de la comunicación virtual.

En este mundo cambiante hay por lo menos dos valores permanentes, cuyo resguardo, guste o no, corresponde al campo del periodismo y, en particular, a las instituciones de enseñanza superior, como la Universidad de Chile, que desde su condición de entidad pública, laica, pluralista, y con su vocación de servicio, entienden que la comunicación social es demasiado importante como para dejarla en manos del mercado. Esos valores, estrechamente relacionados, son el buen periodismo y la ética. El uno no se realiza sin la otra. Escribir bien, ejercer rigor conceptual y usar adecuadamente el lenguaje (tanto escrito como audiovisual) es un requisito de calidad que responde en última instancia al derecho de la ciudadanía a estar informada. Esto coloca como referente un deber ser, una deontología, que se expresa en su dimensión social. Allí, la ética pasa a ser el eje, el tronco que incorpora el compromiso con la verdad y a la vez las responsabilidades que acarrea ese compromiso de cara a la sociedad y que tienen como fundamento de última y primera instancia a los derechos humanos.

La globalización llegó acompañada de reacomodos del llamado orden (o desorden) internacional, donde el poder unipolar estimula la insurgencia de integrismos de variado signo que pretenden actuar, cada uno, bajo cánones de una moral de conveniencia, en un juego donde las manipulaciones van desde lo global (las mentiras del gobierno de George W. Bush sobre armas de destrucción masiva para invadir Irak, por ejemplo), hasta los escenarios locales. Los montajes gráficos, las cámaras ocultas y las interceptaciones telefónicas, representan hoy instrumentos y procedimientos de "construcción de noticias" que exacerban las disputas entre lo público y lo privado, pero que también operan como

\footnotetext{
* Directora del Instituto de la Comunicación e Imagen. Universidad de Chile
} 
engranajes de operaciones mediáticas orquestadas por los poderes, en especial los poderes fácticos.

El Dossier temático del presente número de Comunicación y Medios busca instalar elementos para la reflexión sobre el amplio espectro de posibilidades que abren las nuevas tecnologías para la comunicación social, pero también hacerse cargo de los ineludibles desafíos que éstas representan en el terreno ético. No se trata, ni por mucho, de asuntos que puedan ser agotados en un conjunto de artículos, más aún cuando constituyen objetos de reflexión diaria en nuestro quehacer académico y profesional. Sin embargo, los materiales que aquí encontrará el lector contribuirán a acotar un debate en que están invitados a participar no sólo las organizaciones profesionales y los dueños de los medios, sino también, y principalmente las diversas expresiones de la sociedad civil.

Los conceptos que vierte el periodista colombiano Javier Darío Restrepo en la sección Entrevista -que acompaña al Dossier- son una valiosa contribución a dicho debate de parte de una de las voces más autorizadas en temas de ética periodística. Lo mismo puede decirse de Abraham Santibáñez, autor del artículo que abre la revista. Otros ocho escritos, a cargo de académicos del Instituto de la Comunicación e Imagen de la Universidad de Chile y de otras entidades, entregan diversos puntos de vista sobre las nuevas tecnologías de la información y sus relaciones, en algunos casos con la ética, y con otros desafíos de la globalización, como son la brecha digital o la socialización de los avances informáticos para construir sociedades más equitativas. Particular relieve cobran los trabajos de académicos de universidades de España, escritos especialmente para Comunicación y Medios.

En la sección Artículos, otros siete textos dan cuenta de diversas aproximaciones a los estudios sobre comunicación y a fenómenos culturales y mediáticos, tanto desde los espacios convencionales de la reflexión académica en nuestro campo, como a través de renovadas miradas que llegan de la videomúsica o el cine.

Como siempre, en la sección Referencias incluimos reseñas y comentarios de libros y obras audiovisuales que sin duda constituyen un aporte para nuestros lectores.

Finalmente, un homenaje de Comunicación y Medios al maestro del periodismo escrito, Ryszard Kapuscinski, fallecido hace unos meses, a los 74 años, quien reflexiona en torno a algunos de los tópicos que aquí tocamos: "Internet ofrece un periodismo de información inmediata y sirve para acelerar la transmisión de datos. Sin embargo, acumular una enorme cantidad de información no sustituye el razonamiento, la reflexión, el entendimiento. Corremos el peligro de llegar a una situación en la cual los datos abunden pero nuestra imaginación no sepa cómo procesarlos y utilizarlos en nuestra vida práctica. Esa contradicción sintetiza el drama de nuestra cultura: acumulamos más y más datos, más y más rápìdamente, pero hacerlo no nos ayuda a entender ni mejorar el mundo". 